\title{
Identification of Two Additional Behaviorally Active Gland Constituents of Female Diatraea saccharalis (Fabricius) (Lepidoptera: Crambidae)
}

\author{
Maycon R. da Silva, ${ }^{a}$ Angela M. P. Cortes, ${ }^{a}$ Glenn P. Svensson, ${ }^{b}$ Christer Löfstedt,${ }^{b}$ \\ Eraldo R. Lima ${ }^{c}$ and Paulo H. G. Zarbin ${ }^{\odot *, a}$
}

\author{
${ }^{a}$ Departamento de Química, Universidade Federal do Paraná, CP 19081, 81531-990 Curitiba-PR, Brazil \\ ${ }^{b}$ Department of Biology, Lund University, SE-223 62 Lund, Sweden \\ ${ }^{c}$ Departamento de Entolomogia, Universidade Federal de Viçosa, Av. P. Rolfs s/n, Centro, \\ 36570-900 Viçosa-MG, Brazil
}

\begin{abstract}
The sugarcane borer, Diatraea saccharalis (Fabricius), is the major pest insect attacking sugarcane crops in Brazil. Population control by insecticide treatment is not efficient due to simultaneous presence of all developmental stages of the insect throughout the year, and alternative control methods are needed. Two female-produced sex pheromone components, $(Z, E)$-hexadeca-9,11-dienal and (Z)hexadec-11-enal, have previously been reported to elicit antennal activity and behavioral response of males in flight tunnel experiments. However, the attractiveness of these compounds in field tests has been very low. In this study, two additional female-produced compounds in $D$. saccharalis eliciting consistent antennal response in males were identified as (Z)-hexadec-9-enal and hexadecanal. In flight tunnel assays, the behavioral response to a quaternary blend was significantly higher when compared with the previously identified binary blend. Subtracting $(Z)$-hexadec-9-enal or hexadecanal from the full blend did not reduce attraction, indicating redundancy in the communication channel. We conclude that additional compounds are part of the sex pheromone of D. saccharalis, which may improve the efficiency of trap lures for monitoring of this pest.
\end{abstract}

Keywords: electrophysiology, bioassay, sugarcane pest, sex pheromone

\section{Introduction}

The sugarcane borer, Diatraea saccharalis (Fabricius) (Lepidoptera: Crambidae), is the major pest in sugarcane plantations in Brazil. For this insect, population control using pesticides is inefficient due to simultaneous presence of all developmental stages of the insect throughout the year. In addition, larval and pupal stages are protected inside the plant. ${ }^{1,2}$ Many strategies have been developed in order to decrease the damage caused by $D$. saccharalis in sugar cane crops, including biological control with the braconid larval parasitoid Cotesia flavipes (Cameron) (Hymenoptera: Braconidae), manual collection of the larvae and cultivation of genetically modified varieties of sugarcane. ${ }^{3}$ Pheromone-based methods for population monitoring and control have been successfully applied to manage important agricultural pests, ${ }^{4,5}$ and such methods may be implemented in integrated pest management (IPM) programs for $D$. saccharalis in sugarcane plantations.

*e-mail: pzarbin@ufpr.br
Two gland constituents of female D. saccharalis have been reported to elicit antennal activity in conspecific males, and were identified as $(Z, E)$-hexadeca-9,11-dienal (Z9,E11-16:Ald) ${ }^{6,7}$ and (Z)-hexadec-11-enal (Z11-16:Ald) ${ }^{8}$ In wind tunnel bioassays, a 10:1 blend of Z9,E11-16:Ald and Z11-16:Ald elicited the same level of attraction of D. saccharalis males as the female extract. ${ }^{8}$ However, low attractiveness of this blend observed in field tests indicates that the identification of the sex pheromone is incomplete. Thus, the goal of this work was to reinvestigate the sex pheromone of $D$. saccharalis using electrophysiological and behavioral analyses, in order to identify additional female-produced compounds that might be important for the attraction of males of this species.

\section{Experimental}

Insect origin and rearing

Diatraea saccharalis were provided by the Entomology Department of the Superior School of Agriculture Luiz de 
Queiroz at University of São Paulo, Brazil. Insects used for pheromone gland analyses and electrophysiological analyses were transported to the Laboratory of Semiochemicals at Federal University of Paraná, Brazil, and reared at $24 \pm 2{ }^{\circ} \mathrm{C}, 70 \%$ relative humidity and a $12: 12$ light:dark cycle. Insects used for flight tunnel experiments were transported to Department of Biology, Lund University, Sweden, and reared at $24{ }^{\circ} \mathrm{C}, 60 \%$ relative humidity and a 14:10 light:dark cycle. Larvae were fed on artificial diet made of soy flour, sugar and wheat germ. Pupae were separated by sex before emergence and a $10 \%$ solution of sucrose was provided to adults.

\section{Synthetic standards}

Synthetic standards of Z9,E11-16:Ald and all the monoene aldehydes ( $E$ and $Z$ isomers from $\Delta 7$ to $\Delta 11-C 16$ aldehydes) were purchased from Pherobank (Wageningen, The Netherlands) with $\geq 95 \%$ purity. Hexadecanal (16:Ald) was obtained by the hydrogenation of Z11-16:Ald with $\geq 95 \%$ purity. ${ }^{9,10}$

\section{Pheromone gland extraction}

Extractions were performed on 2-4 days old virgin calling females, between the $5^{\text {th }}$ and $7^{\text {th }}$ hours of the scotophase. ${ }^{8}$ Pheromone glands were excised with forceps and transferred to a glass tube $(1 \mathrm{~mL})$ containing hexane for extraction ( $10 \mu \mathrm{L}$ hexane per gland), at room temperature during 20 min. ${ }^{11}$ The solvent was then recovered and transferred to a new glass tube to be stored. Pooled extracts including 103 or 130 glands were stored at $-20{ }^{\circ} \mathrm{C}$ until used for analysis/experiments.

\section{Electrophysiological analysis of female gland extracts}

Analyses by gas chromatography coupled with electroantennographic detection (GC-EAD) were performed using a Shimadzu GC-2010 GC equipped with a J\&W Scientific Inc. DB-5 column $(30 \mathrm{~m} \times 0.25 \mathrm{~mm}$ internal diameter $\times 0.25 \mu \mathrm{m}$ film thickness) coupled with a Syntech electroantennography system (Syntech, Kirchzarten, Germany). Samples were injected in splitless mode. The capillary column was used under the following analytical conditions: initial temperature of $100{ }^{\circ} \mathrm{C}$ for $1 \mathrm{~min}$, increasing by $10{ }^{\circ} \mathrm{C} \mathrm{min}^{-1}$ to $270{ }^{\circ} \mathrm{C}$, which was kept for $7 \mathrm{~min}$. Helium was used as carrier gas at a column head pressure of $170 \mathrm{kPa}$. The column effluent was split 1:1 with half of the sample going to the flame ionization detector (FID) at $270{ }^{\circ} \mathrm{C}$, and the other half going through a heated transfer line $\left(270{ }^{\circ} \mathrm{C}\right)$ into a humidified airstream
(300 $\mathrm{mL} \mathrm{min}^{-1}$ ) reaching the antennal preparation of a male. The antenna was fixed between two stainlesssteel electrodes using electrically conductive gel (Signa gel, Parker Labs., NJ, Fairfield, USA). Recordings were analyzed using the Syntech electroantennography GC-EAD32 software (version 4.6).

\section{Chemical analysis}

Gas chromatography-mass spectrometry (GC-MS) analyses were performed on a Shimadzu QP-5050A GC-MS equipped with $70 \mathrm{eV}$ electron impact mode and operated in splitless mode. A DB-5 column was used under the following analytical conditions: initial temperature of $50{ }^{\circ} \mathrm{C}$ for $1 \mathrm{~min}$; increasing by $7{ }^{\circ} \mathrm{C} \mathrm{min}{ }^{-1}$ to $250{ }^{\circ} \mathrm{C}$, which was held for $10 \mathrm{~min}$. Helium was used as carrier gas. The gland constituents that elicited antennal responses in GC-EAD recordings were identified through comparison of Kováts retention indexes (RI) and mass spectra of the libraries NIST27 and NIST147. The double bond position and geometry of monoenes were also confirmed by co-injection and by GC-EAD responses from male $D$. saccharalis employing authentic standards of all possible monoene isomers ( $E$ and $Z$ isomers of $\Delta 7, \Delta 8$, $\Delta 9, \Delta 10$ and $\Delta 11$ monoenes). ${ }^{12}$

Additional GC analyses were performed using a Shimadzu GC-2010 at the same temperature setting as for the GC-EAD analysis. The concentration and blend ratio of pheromone components were determined based on the area of GC peaks, and calibration curves were calculated based on authentic standards. A series of saturated C10-C26 hydrocarbons was injected with the samples to calculate the Kováts index (KI) of electrophysiologically active compounds.

\section{Flight tunnel assays}

The behavioral response of $D$. saccharalis males when exposed to female gland extract or blends of synthetic candidate pheromone components was evaluated using a $0.9 \times 0.9 \times 3 \mathrm{~m}$ (height $\times$ width $\times$ length) Plexiglas flight tunnel at Lund University, Sweden. The assays were performed using 2-4 days old virgin males between the $6^{\text {th }}$ and $7^{\text {th }}$ hours of the scotophase at $1.5 \mathrm{Lux}, 24-25^{\circ} \mathrm{C}$ and $65-70 \%$ R.H. and $0.3 \mathrm{~ms}^{-1}$ airflow. Males were transferred to the flight tunnel room and individually placed in small glass cylinders $45 \mathrm{~min}$ before the beginning of the scotophase. An odor stimulus was prepared with $10 \mu \mathrm{L}$ of a test solution loaded onto a small strip of filter paper (experiments 1-3) or $100 \mu \mathrm{L}$ of a test solution loaded on a red rubber septum $(11 \times 5$ mm, No. 224100-020, Wheaton Science Products, 
Millville, NJ, USA) (experiment 4), which was placed on a $35 \mathrm{~cm}$-high metal holder at the upwind end of the flight tunnel. The odor stimulus was reapplied to the filter paper before a new male was assayed. Six behaviors were recorded during the experiments: (i) no response; (ii) activation (movement and wing fanning); (iii) take off (leaving the glass cylinder); (iv) orientation (upwind flight within the odor plume); (v) orientation at least $10 \mathrm{~cm}$ from odor source and (vi) source contact (touching or landing on the source). After taking off, a male was allowed $5 \mathrm{~min}$ to reach the odor source.

Thirty males were used per treatment in all experiments, and each male was used only once. In the first experiment, males were tested against 1 female equivalent (1 FE) of gland extract, a 10:1 blend of Z9,E11-16:Ald and Z11-16:Ald, and a 10:1:1:1 blend of Z9,E11-16:Ald, Z11-16:Ald, Z9-16:Ald and 16:Ald, at a dose corresponding to $1 \mathrm{ng}$ of $Z 9, E 11-16$ :Ald. In the second experiment, the same three treatments were used, but the dose of synthetic compounds in the binary and quaternary blends corresponded to $100 \mathrm{pg}$ of Z9,E11-16:Ald. In the third experiment, the quaternary blend and two ternary blends, where either Z9-16:Ald or 16:Ald had been removed from the full blend, were used at $100 \mathrm{pg}$ dose of Z9,E11-16:Ald. The fourth and last experiment included the full blend at different amounts (20, 100 or $500 \mathrm{ng}$ of Z9,E11-16:Ald) applied onto rubber septa.

For each experiment, differences in the behavioral response between treatments were tested for statistical significance using a Chi-square test. All statistical analyses were performed using the software BioEstat 5.3.13

\section{Results}

Identification of female gland constituents

The GC-EAD analyses of female pheromone gland extracts of D. saccharalis revealed four compounds eliciting consistent antennal activity in conspecific males (Figure 1a). In subsequent chemical analyses by GC-MS, the most abundant compound with strongest antennal activity was identified as Z9,E11-16:Ald based on Kováts retention index, fragmentation pattern, and comparison with synthetic standard. The following features were observed: $\mathrm{t}_{\mathrm{R}}$ (retention time) 13.26; KI 1868; and fragment ions at $\mathrm{m} / \mathrm{z}$ (\%): $236\left(\mathrm{M}^{+}, 13\right), 123$ (8.1), 109 (13.4), 95 (3.7), 81 (72.3), 67 (100), 55 (29.4).

Of the three minor compounds in the extract eliciting an antennal response, the second eluting compound was identified as the previously published ${ }^{8}$ Z11-16:Ald based on the following features: $t_{R} 13.03$; KI 1846; and fragment ions at $m / z(\%): 238\left(\mathbf{M}^{+}, 3\right), 220(8), 135(8), 121$ (15), 98 (29), 81 (42), 69 (50), 55 (100), 41 (59). Additional GC-EAD analyses using Z11-16:Ald or E11-16:Ald as stimulus were performed, confirming that antennae of males only respond to Z11-16:Ald (Figure 1b).

The first eluting compound in the extract was a compound not previously reported in the pheromonal blend, and it was identified as Z9-16:Ald based on the following features: $\mathrm{t}_{\mathrm{R}} 12.56$; $\mathrm{KI}$ of 1800 ; and fragment ions at $\mathrm{m} / \mathrm{z}(\%)$ : $238\left(\mathrm{M}^{+}, 3\right), 220$ (8), 135 (7.5), 121 (15), 98 (29), 81 (42), $69(50), 55$ (100), 41 (59). The position and geometry of the double bond of the compound was confirmed by comparative GC-EAD analyses employing a series of possible isomers whose Kováts indexes were closely related to that detected for the natural product (a range of $E$ and $Z$ isomers from $\Delta 7$ to $\Delta 10$-C16 aldehydes). ${ }^{12}$ The analyses indicated that only the Z9-16:Ald data perfectly matched the natural product present in the female gland extract (Figures 1c and 1d).

The third eluting compound in the extract was identified as the saturated 16:Ald based on the following features: $\mathrm{t}_{\mathrm{R}}$ 13.07; KI 1850; and fragment ions at $m / z(\%): 240\left(\mathrm{M}^{+}\right.$, 0.18), 194 (4), 138 (10), 124 (18), 110 (22), 96 (68), 82 (98), 68 (54), 57 (100), 43 (87). All four identified compounds that elicited antennal activity were co-injected with the female pheromone gland extract (Figure 1d). The relative ratios of Z9,E11-16:Ald, Z11-16:Ald, Z9-16:Ald and 16:Ald in the extracts were determined to be ca. 10:1:1:1.

\section{Flight tunnel assays}

In all experiments, no statistically significant differences between treatments were observed for the initial behaviors (no response, activation, take off, orientation), but there were generally distinct differences between treatments in number of males reaching the odor source. In the first experiment, significantly more males reached the source of female extract when compared with both the binary blend $\left(\chi^{2}\right.$ (Chi square value $)=21.696$, d.f. (degree of freedom value) $=1, p<0.0001$ ) and the quaternary blend $\left(\chi^{2}=19.288\right.$, d.f. $\left.=1, p<0.0001\right)$ at $1 \mathrm{ng}$ dose, but there was no statistical difference observed between the binary blend and the quaternary blend treatments $\left(\chi^{2}=0.111\right.$, d.f. $=1$, $p=0.70$ ) (Figure 2a). In the second experiment, when using a ten times lower dose of synthetic compounds, a similar number of males reached the sources of quaternary blend and female gland extract $\left(\chi^{2}=0.098\right.$, d.f. $\left.=1, p=0.75\right)$, whereas significantly fewer males reached the source of the binary blend, both when compared with female extract $\left(\chi^{2}=7.177\right.$, d.f. $\left.=1, p=0.007\right)$ and the quaternary blend $\left(\chi^{2}=5.711\right.$, d.f. $\left.=1, p=0.01\right)$ (Figure 2b). 
(a)

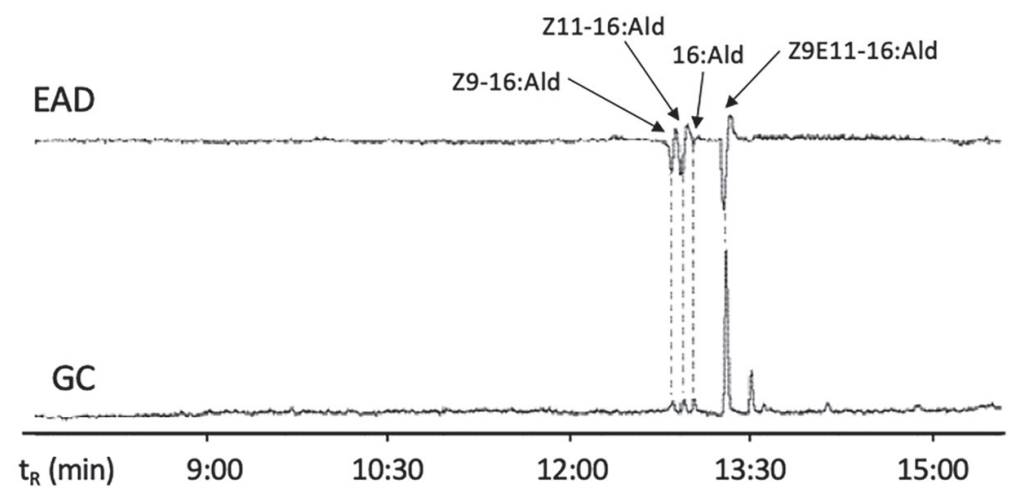

(b)

(c)

EAD
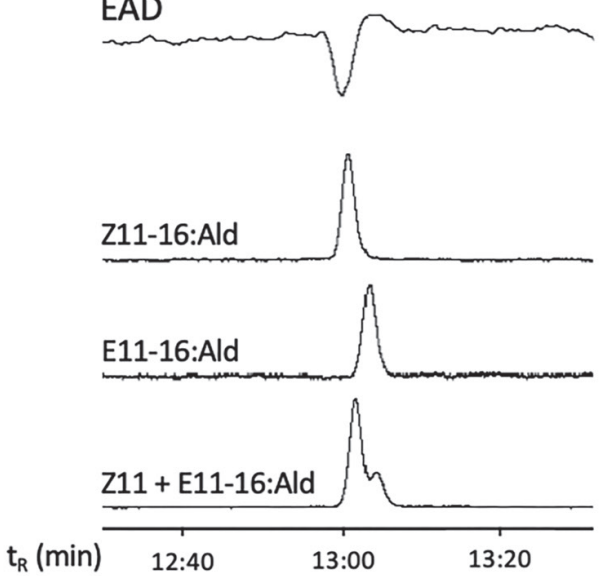

EAD

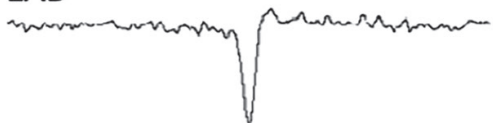

29-16:Ald
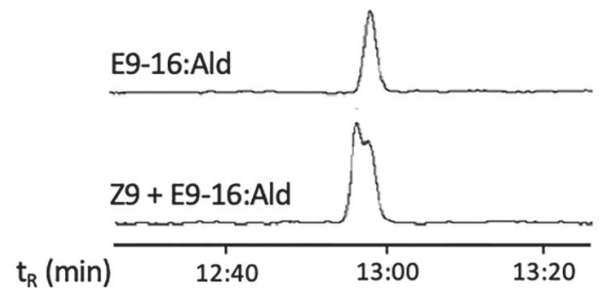

(d)
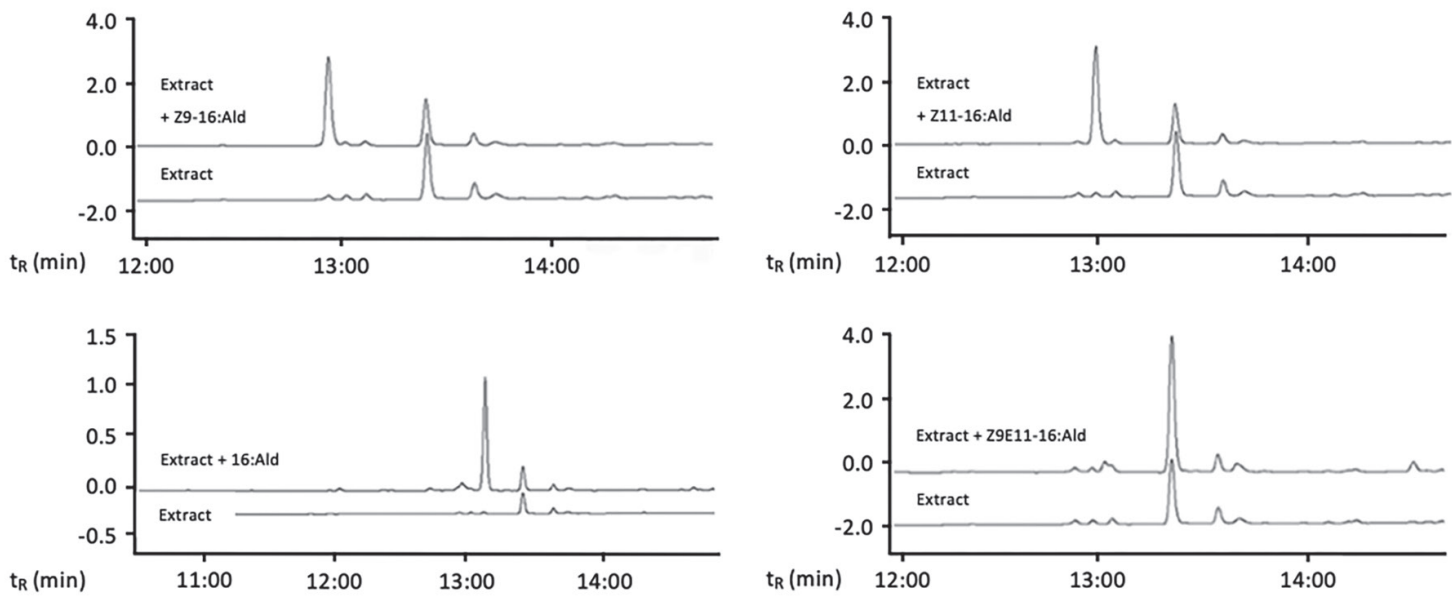

Figure 1. GC-EAD/GC-FID analyses of Diatraea saccharalis female pheromone gland extracts and synthetic reference compounds using male antennae as detectors. (a) GC-EAD analysis of $1 \mu \mathrm{L}$ aliquot from a pooled extract from 103 female pheromone glands extract showing antennal response to four compounds. (b) Comparative GC-EAD analysis of the synthetic isomers Z11-16:Ald and E11-16:Ald on male antennae. (c) GC-EAD analysis of the isomers 29-16:Ald and E9-16:Ald on male antennae. (d) Comparison of the GC-FID chromatograms of the co-injection of the identified EAD active compounds (synthetic standards) and female pheromone gland extract. Column DB-5 (30 m × $0.25 \mathrm{~mm} ; 0.25 \mu \mathrm{m})$. 

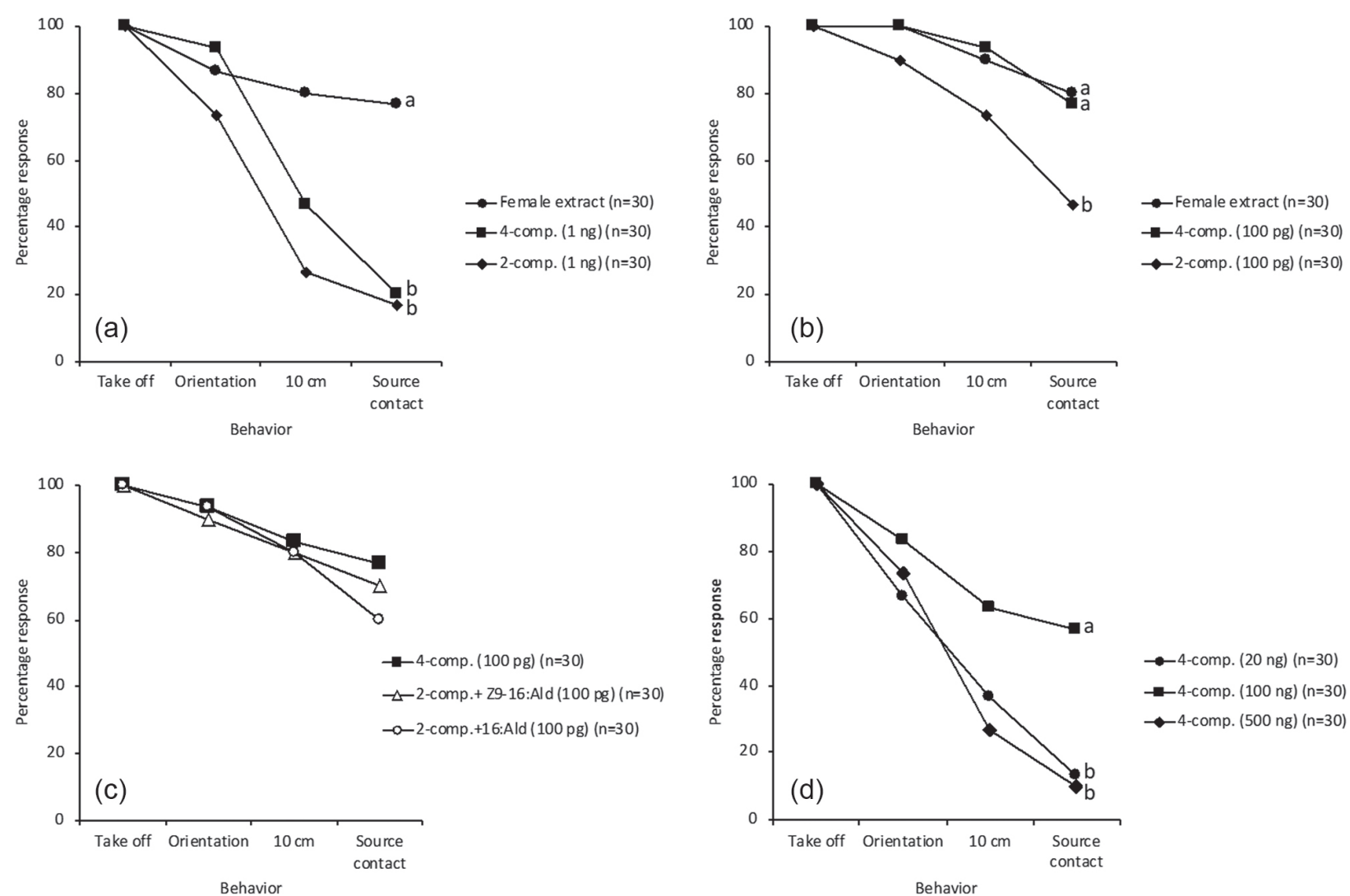

Figure 2. Behavioral responses of Diatraea saccharalis males in the four different flight tunnel experiments. Take off: leaving the glass cylinder; orientation: upwind flight in the odor plume; $10 \mathrm{~cm}$ : orientation flight $10 \mathrm{~cm}$ from the source; source contact: touching or landing on the odor source. Dose in brackets refers to the dose of the major sex pheromone component (Z,E)-hexadeca-9,11-dienal applied on filter paper (assay 1-3) or rubber septum (assay 4). Different letters after treatments within an experiment indicates statistically different source contact rates, based on Chi-square tests $(p<0.05)$.

In the third experiment, no significant difference among treatments was observed regarding source contact $\left(\chi^{2}=1.970\right.$, d.f. $\left.=1, p=0.37\right)$ (Figure 2c). Finally, when testing different doses of the quaternary blend on rubber septa, the $100 \mathrm{ng}$ treatment attracted significantly more males when compared with the $20 \mathrm{ng}$ dose $\left(\chi^{2}=12.381\right.$, d.f. $=1, p<0.001)$ as well as the $500 \mathrm{ng}$ dose $\left(\chi^{2}=14.700\right.$, d.f. $=1, p<0.0001)$. In contrast, no significant difference was observed between male responses to the 20 and $500 \mathrm{ng}$ $\operatorname{doses}\left(\chi^{2}=0.162\right.$, d.f. $\left.=1, p=0.68\right)$ (Figure 2d).

\section{Discussion}

Sex pheromone communication in D. saccharalis has been studied extensively. The major sex pheromone component of this species, Z9,E11-16:Ald, was identified almost 40 years ago, ${ }^{6}$ and this compound has also been identified as the major component of the sex pheromone of D. indigenella (Dyar \& Heinrich). ${ }^{11}$ Due to the low attractiveness of Z9,E11-16:Ald in field tests, several reinvestigations of the pheromone have been performed ${ }^{7,8}$ revealing Z11-16:Ald as an additional gland constituent that elicited male antennal activity in GC-EAD analysis.
In addition, flight tunnel experiments showed that a blend of Z11-16:Ald and Z9,E11-16:Ald was more attractive to males than Z9,E11-16:Ald alone. ${ }^{8}$ In Diatraea spp., Z11-16:Ald has been identified as the major component of the sex pheromone of D. grandiosella (Dyar), ${ }^{14}$ D. considerata $(\text { Heinrich })^{15}$ and D. flavipennella $(\text { Box })^{3}$ and this compound is one of most commonly used compounds for sex pheromone communication in Crambidae moths. ${ }^{16}$

In the present study, two additional female-produced compounds of $D$. saccharalis that elicited antennal activity in males were identified as Z9-16:Ald and 16:Ald (Figure 1a). Addition of these compounds to the blend of Z9,E11-16:Ald and Z11-16:Ald significantly increased attraction of males in flight tunnel assays when compared with the binary blend, and the level of attraction to the quaternary blend was similar to that of the female extract (Figure 2b). In addition, ternary mixtures with Z9-16:Ald or 16:Ald were as attractive to males as the quaternary blend, indicating redundancy in the communication channel (Figure 2c). The compound Z9-16:Ald was also found in the pheromone blend of D. grandiosella ${ }^{14}$ and $D$. flavipennella ${ }^{3}$ and 16:Ald was shown to be part of the sex pheromone blend of D. grandiosella ${ }^{14}$ and D. considerata. ${ }^{15}$ 
The significantly lower attraction of males to the binary blend versus female extract differs from the previous study showing similar attraction of males to these two stimuli. ${ }^{8}$ In our study, the source contact rate to the extract was $77-80 \%$ whereas the source contact rate in the previous study was much lower $(64-68 \%){ }^{8}$ This difference in attraction to the extract stimulus could at least partly explain the different results obtained in the two studies. The use of different lab cultures of moths, and different flight tunnel settings could also contribute to slightly different outcomes of the bioassays.

So far, all five species of Diatraea mentioned above, for which the sex pheromone has been analyzed, produce mixtures of C16-C18 aldehydes as sex pheromone ${ }^{16}$ with efficient trap lures developed for $D$. considerata, ${ }^{15}$ D. flavipennella ${ }^{3}$ and D. grandiosella.$^{14}$ Female D. saccharalis produce the sex pheromone components in minute amounts, and both this study and the previous study $^{8}$ show that very small amounts of compounds are required for optimal attraction of males in a flight tunnel setting. No studies have reported successful capture of D. saccharalis in the field using traps baited with synthetic sex pheromone components. Our flight tunnel experiments using red rubber septa as lures showed promising results, but trapping experiments are needed to evaluate if this improved blend will attract males also in a field setting. The dosage-dependent response detected in the flight tunnel assays also revealed that successful field experiments may rely on precise dosages of test compounds in baits.

\section{Conclusions}

To conclude, the identification of two additional pheromone components, Z9-16:Ald and 16:Ald, awaiting field tests of the complex blends, is a step forward for the elucidation of the chemical communication in D. saccharalis and use of pheromone-based methods in IPM of this major pest of sugarcane crops.

\section{Acknowledgments}

We thank the Entomology Department of the Superior School of Agriculture Luiz de Queiroz at University of São Paulo for sending moth pupae. This work was funded by a CAPES/STINT grant for SwedishBrazilian collaboration (to GPS and PHGZ), and INCTSemioquímicos na Agricultura (CNPq 465511/2014-7; FAPESP 2014/50871-0).

\section{Author Contributions}

responsible for data curation, methodology, software, validation, visualization and writing; Glenn P. Svensson for conceptualization, data curation, project administration, formal analysis funding acquisition, methodology, visualization and writing; Christer Löfstedt for validation, visualization, writing original draft, writing-review and editing; Eraldo R. Lima for methodology, software and writing; Paulo H. G. Zarbin for conceptualization, project administration, formal analysis funding acquisition, visualization, writing original draft, writing-review and editing.

\section{References}

1. https://repository.agrosavia.co/handle/20.500.12324/1766, accessed in July 2020.

2. Palacio-Cortés, A. M.; Zarbin, P. H. G.; Takya, D. M.; Bento, J. M. S.; Guidolin, A. S.; Consoli, F. L.; J. Insect. Physiol. 2010, $56,1624$.

3. Kalinová, B.; Nascimento, R. R.; Hoskovec, M.; Mendonça, A. L.; Silva, E. L.; Freitas, M. R. T.; Cabral-Jr., C. R.; Silva, C. E.; Sant' Ana, A. E. G.; Svatos, A.; J. Appl. Entomol. 2012, 136, 203.

4. Witzgall, P.; Kirsch, P.; Cork, A.; J. Chem. Ecol. 2010, 36, 80.

5. Trematerra, P.; J. Pestic. Sci. 2012, 85, 285.

6. Hammond, A. M.; Fisher, N. H.; Sugar Azucar 1982, 77, 32.

7. Batista-Pereira, L. G.; Santangelo, E. M.; Stein, K.; Unelius, C. R.; Eiras, A. E.; Correa, A.; Z. Naturforsch. 2012, 57, 753.

8. Kalinová, B.; Kindl, J.; Hovorka, O.; Hoskovec, M.; Svatos, A.; J. Appl. Entomol. 2005, 129, 70.

9. Zarbin, P. H. G.; Princival, J. L.; Lima, E. R.; Santos, A. A.; Ambrogi, B. G.; Oliveira, A. R. M.; Tetrahedron Lett. 2004, 45, 239.

10. Zarbin, P. H. G.; Oliveira, A. R. M.; Simonelli, F.; Villar, J. A. F. P.; Delay, O.; Tetrahedron Lett. 2004, 45, 7399.

11. Palacio-Cortés, A. M.; Fonseca, M. G.; Zarbin, P. H. G.; Neotrop. Entomol. 2014, 43, 526.

12. Marques, F. A.; McElfresh, J. S.; Millar, J. G.; J. Braz. Chem. Soc. 2000, 11, 592.

13. BioEstat 5.3; Instituto Mamirauá, Belém, 2007.

14. Hedin, P. A.; Davis, F. M.; Dickens, J. C.; Burks, M. L.; Bird, T. G.; Knutson, A. E.; J. Chem. Ecol. 1986, 12, 2051.

15. Gries, R.; Dunkelblum, E.; Gries, G.; Baldilla, F.; Hernandez, C.; Alvarez, F.; Perez, A.; Velasco, J.; Oehlschlager, A. C.; J. Appl. Entomol. 1998, 122, 265.

16. https://lepipheromone.sakura.ne.jp/pdb_top_eng.html, accessed in July 2020.

Maycon R. da Silva and Angela M. P. Cortes were 